\title{
Efektivitas Progressive Muscle Relaxation terhadap Tekanan Darah pada Penyakit Hipertensi
}

\author{
Ricky Zainuddin", Ayu Fransisca Aliwu², Rini Rachmawaty², Yuliana Syam² \\ ${ }^{1}$ Mahasiswa Program Studi Magister Ilmu Keperawatan, Universitas Hasanuddin Makassar \\ ${ }^{2}$ Mahasiswa Akademik Keperawatan, Yayasan Pendidikan Makassar \\ ${ }^{2}$ Dosen Program Studi Magister Ilmu Keperawatan, Universitas Hasanuddin Makassar \\ Email: rickyz.rz22@gmail.com
}

Received 3 September 2018; Accepted 4 September 2018; Published 6 November 2018

\begin{abstract}
Introduction: Progressive Muscle Relaxation is a muscle relaxation technique that does not require imagination, perseverance or suggestion. Muscle relaxation is a skill that can be learned and used to reduce or eliminate tension and stimulate a sense of comfort without being dependent on things / subjects outside of itself. This Progressive Muscle Relaxation technique uses deep breathing relaxation techniques to relax the muscles. Objectives: With this Progressive Muscle Relaxation exercise, the condition of these muscles is in a relaxed state and this will improve organ function so that it is normal again, there are several types of Progressive Muscle Relaxation movement including: reduce pain, reduce blood pressure, reduce anxiety, and reduce stress. Method: this study explores evidence published in electronic data: Pubmed, google scholar. By using a search strategy, we identified 17 potentially and relevant articles. Five studies were included in the last analysis. Results: we were able to see a significant effect in reducing blood pressure in hypertensive disease receiving Progressive Muscle Relaxation compared to the group that did not receive Progressive Muscle Relaxation training. Conclusion: These results show that Progressive Muscle Relaxation can be a nonpharmacological therapy in reducing blood pressure in Hypertension and nurses can participate in providing this training.
\end{abstract}

Keywords: Blood pressure, hypertension, progressive muscle relaxation

Copyright $\odot 2018$ STIKes Surya Mitra Husada

All right reserved.

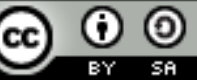

This is an open-acces article distributed under the terms of the Creative Commons AttributionShareAlike 4.0 International License.

\section{PENDAHULUAN}

Hipertensi sering disebut sebagai pembunuh gelap / silent killer karena termasuk penyakit yang mematikan, karena sering kali penderita hipertensi tidak merasakan sesuatu gangguan ataupun gejala. Hipertensi dapat menyerang siapa saja, baik muda maupun tua (Triyanto, 2014). Hipertensi merupakan salah satu penyakit paling mematikan di dunia. Sebanyak 1 milyar orang di dunia menderita penyakit ini. Diperkirakan jumlah penderita hipertensi akan meningkat menjadi 1,6 milyar menjelang tahun 2025 (Pudiastuti, 2013).

Menurut ISH (International Society of Hypertension), saat ini terdapat 600 juta penderita hipertensi di seluruh dunia, dan 3 juta di antaranya meninggal setiap tahun (Muliyati, Syam, \& Sirajuddin, 2010). Menurut American Heart Association $\{A H A\}$, penduduk Amerika yang berusia 
diatas 20 tahun menderita hipertensi telah mencapai angka hingga 74,5 juta jiwa. Menurut data WHO, di seluruh dunia sekitar 972 juta orang atau $26,4 \%$ orang di seluruh dunia mengidap hipertensi, angka ini kemungkinan akan meningkat menjadi 29,2\% di tahun 2025. Dari 972 juta pengidap hipertensi, 333 juta berada di negara maju dan 639 juta sisanya berada di negara berkembang, termasuk Indonesia (Zaenurrohmah, 2017). Sedangkan pada tahun 2016 hipertensi di Sulawesi Selatan mencapai 554 jiwa (Makassar, 2017).

Penanganan hipertensi hingga saat ini yang diberikan di Rumah Sakit - Rumah Sakit maupun di Puskesmas - Puskesmas adalah dengan pemberian terapi farmakologi. Salah satu terapi farmakologi yang paling sering diberikan yaitu captopril dewasa dosis yang diberikan yaitu $12,5 \mathrm{mg}-$ $25 \mathrm{mg}, 2-3 \mathrm{x}$ sehari, akan tetapi pengobatan ini memiliki efek samping seperti batuk kering, pusing, sakit kepala, dan lemas (wijaya, 2013). Berdasarkan efek samping yang sering muncul akibat terapi farmakologi yang dapat memperburuk kondisi kesehatan yang akan datang, karena itu sangat diperlukan terapi non-farmakologi yang dapat menurunkan tekanan darah serta meminimalisir efek samping dari pengobatan farmakologi. Salah satu terapi non farmakologi yang dapat menurunkan tekanan darah yaitu terapi PMR (Progresive Muscle Relaxation) (Triyanto, 2014).

PMR (progressif muscle relaxation) merupakan terapi relaksasi yang dapat menurunkan rate detak jantung, tekanan darah, mengontrol nyeri, serta mengurangi ketegangan otot. Latihan PMR sangat sederhana dan mudah dipelajari, karena latihan ini dapat digunakan di klinik rawat jalan, di rumah, atau pengobatan rawat inap pada pasien hipertensi. PMR memiliki efek langsung dalam menurunkan denyut nadi, tekanan darah sistolik dan tekanan darah diastolic setelah mengikuti latihan. Selain itu PMR memiliki manfaat psikologis yaitu dapat mengurangi kecemasan, stress, depresi dan mengurangi perilaku agresif pada pasien yang mengalami cacat mental (Sheu, Irvin, Mar, Lin, \& Mar, 2003)

Latihan Progressive Muscle Relaxation (PMR) yaitu terapi yang berfokus dalam mempertahankan konsentrasi yang dalam serta relaksasi tubuh yang baik.Terapi PMR ini melibatkan kontraksi dan relaksasi berbagai kelompok otot tubuh mulai dari ujung kepala sampai ujung kaki maupun dari ujung kaki hingga ujung kepala. Untuk meregangkan otot secara progresif, dimulai dengan menegangkan dan meregangkan kumpulan otot utama tubuh. Dengan cara ini, maka akan membuat menormalkan kembali fungsi - fungsi organ tubuh dan membuat tubuh menjadi rileks (Resti, 2014).

PMR dapat menurunkan hipertensi dengan cara kerja sistem simpatetis dan parasimpatetis. Sistem saraf simpatetis bekerja dengan cara meningkatkan rangsangan atau memacu organ-organ tubuh, memacu meningkatnya denyut jantung dan pernafasan, menimbulkan penyempitan pembuluh darah tepi (pheripheral), pembesaran pembuluh darah pusat, menurunkan suhu tubuh, meningkatkan daya tahan kulit, dan juga akan menghambat proses digestif dan seksual, sedangkan sistem saraf parasimpatetis menstimulasi turunnya semua fungsi yang dinaikkan oleh saraf simpatetis, dan menstimulasi naiknya semua fungsi yang diturunkan oleh saraf simpatetis. Pada waktu orang mengalami ketegangan dan kecemasan yang bekerja adalah sistem saraf simpatetis, sedangkan pada waktu rileks yang bekerja adalah sistem saraf parasimpatetis (Purwanto, 2006).

\section{METODE PENCARIAN DAN KRITERIA SELEKSI ARTIKEL}

Tinjauan literatur dilakukan melalui penelusuran hasil-hasil publikasi ilmiah pada rentang tahun 2010-2017 menggunakan database pubmed, google scholar. Pada database pubmed dengan memasukkan keyword 1 "Progressive Muscle Relaxation" didapatkan 2.046 artikel. Keyword 2 "blood pressure" didapatkan 579.950 artikel. Keyword 3 dilakukan penggabungan keyword 1, dan 2, yaitu "Progressive Muscle Relaxation AND blood pressure" didapatkan 153 artikel. Setelah dilakukan pencarian artikel, selanjutnya dilakukan pembatasan jumlah artikel sesuai kriteria penelitian dengan langkah-langkah : LIMIT clinical Trial didaptkan 48 artikel. LIMIT Abstract didapatkan 46 artikel. LIMIT full text didapatkan 31 artikel. LIMIT to date (2010-2017) didapatkan 5 artikel. LIMIT of humans didapatkan 2 artikel.

Pada database google scholar dengan memasukkan keyword 1 "Progressive Muscle Relaxation" ditemukan 22.700 artikel. Keyword 2 "Progressive Muscle Relaxation AND Blood Pressure" ditemukan 7.400 artikel. Setelah dilakukan pencarian artikel, selanjutnya dilakukan 
pembatasan jumlah artikel LIMIT to date (after 2016) ditemukan 730 artikel. LIMIT relevansi ditemukan 15 artikel.

\section{PEMBAHASAN}

\section{Hipertensi}

Hipertensi merupakan penyakit yang timbul akibat adanya interaksi dari berbagai faktor risiko yaitu: umur, jenis kelamin, obesitas, alkohol, genetik, stres, asupan garam, merokok, pola aktivitas fisik, penyakit ginjal dan diabetes melitus. Oleh karena itu penyakit hipertensi timbul karena adanya interaksi dari berbagai faktor yang telah disebutkan diatas. Salah satu faktor yang lebih berpengaruh atau berperan terhadap timbulnya hipertensi tidak dapat diketahui dengan pasti (Sinubu, Risky Brian dan Rondonuwu, 2015).

Menurut ISH (International Society of Hypertension), saat ini terdapat 600 juta penderita hipertensi di seluruh dunia, dan 3 juta di antaranya meninggal setiap tahun (Muliyati et al., 2010). Menurut American Heart Association $\{A H A\}$, penduduk Amerika yang berusia diatas 20 tahun menderita hipertensi telah mencapai angka hingga 74,5 juta jiwa. Menurut data WHO, di seluruh dunia sekitar 972 juta orang atau $26,4 \%$ orang di seluruh dunia mengidap hipertensi, angka ini kemungkinan akan meningkat menjadi 29,2\% di tahun 2025. Dari 972 juta pengidap hipertensi, 333 juta berada di negara maju dan 639 juta sisanya berada di negara berkembang, termasuk Indonesia (Zaenurrohmah, 2017). Sedangkan pada tahun 2016 hipertensi di Sulawesi Selatan mencapai 554 jiwa (Makassar, 2017)

\section{Progressive Muscle Relaxation}

Progressive Muscle Relaxation adalah teknik relaksasi otot bagian dalam yang tidak memerlukan imajinasi, ketekunan ataupun sugesti. Teknik relaksasi progresif memiliki 14 gerakan yang dilakukan selama 15-30 menit (Trisnowiyanto, 2015). Relaksasi otot progresif menurut Jacobson adalah suatu keterampilan yang dapat dipelajari dan digunakan untuk mengurangi atau menghilangkan ketegangan dan mengalami rasa nyaman tanpa tergantung pada hal/subjek diluar dirinya. PMR merupakan salah satu teknik pengelolaan yang dasarkan pada cara kerja sistem simpatetis dan parasimpatetis. Teknik relaksasi menghasilkan respon fisiologis yang terintegrasi dan juga mengganggu bagian dari kesadaran yang dekenal sebagai "respon relaksasi Benson". Respon relaksasi diperkirakan menghambat sistem saraf otonom dan sistem saraf pusat dan meningkatkan aktivitas parasimpatis yang dikarakteristikkan dengan menurunnya otot rangka, tonus otot jantung dan mengganggu fungsi neuroendokrin.

Progressive Muscle Relaation pada awalnya diperkenalkan oleh Jacobson pada tahun 1938 yang kemudian dimodifikasi pada tahun 1973 oleh Bernstein dan Borkovec dan sejak saat itu, bentuk PMR dibuat dalam buku buku teks, pers, dan internet (Kwekkeboom, Hau, Wanta, \& Bumpus, 2008). Teknik relaksasi ini merupakan teknik relaksasi yang paling sederhana dan mudah dipelajari. Teknik Progressive Muscle Relaation ini menggunakan teknik relaksasi nafas dalam untuk merelaksasikan otot - otot (Akmeşe \& Oran, 2014).

\section{PEMBAHASAN ARTIKEL TERKAIT}

Hasil penelitian yang dilakukan oleh (Sheu et al., 2003), bertujuan meneliti efek Progressive Mescle Relaxation (PMR) dan status psikososial, dalam menurunkan tekanan darah dengan diagnose hipertensi di rumah sakit pendidikan di kota koahsiung Taiwan Selatan. Jumlah sampel 40 orang dengan usia $\leq 18$ tahun yang dirawat di rumah sakit pendidikan di kota koahsiung Taiwan Selatan. Pada hasil penelitian menunjukan pelatihan PMR memiliki efek langsung dalam menurunkan denyut nadi 2,35 ketukan/menit, sedangkan tekanan darah sistolik $5,44 \mathrm{mmHg}$ dan tekanan darah diastolic $3,48 \mathrm{mmHg}$. Setelah 4 minggu pelatihan terjadi penurunan denyut nadi 2,9 ketukan/menit, sedangkan pada tekanan darah sistolik 5,1 mmHg dan tekanan darah diastolic $3.1 \mathrm{mmHg}$. PMR secara siknifikan menurunkan presepsi paisen terhadap stress dan meningkatkan presepsi mereka tentang kesehatan dengan hasil akhir $(p<0$ 1). Sehingga dapat disimpulkan bahwa PMR efektif dalam menurunkan 
tekanan darah bagi pasien hipertensi esensial dan perawat dapat menggunakan PMR dalam meningkatkan fungsi independen mereka serta kualitas hidup mereka.

Penelitian lain dilakukan oleh (Aalami, Jafarnejad, \& Modarresgharavi, 2016), penelitian ini bertujuan untuk menilai efek Progressive Muscle Relaxation (PMR) dan Breathing Control pada ibu hamil dengan hipertensi dipusat kesehatan Masyhad dan rumah sakit Pemerintah. Jumlah sampel yang digunakan 30 orang dengan usia kehamilan 20 minggu. Pada hasil penelitian yan dilakukan selama 4 minggu dengan hasil pada PMR yaitu tekanan darah sistolik dari 131,3 ke 117,2 sedangkan diastolic dari 79,2 ke 72,3. Hasil untuk Breathing Control yaitu sistolik 131,05 ke 120,5 sedangkan diastlik 80,1 ke 76,5 dengan hasil akhir yang didapatkan kolompok PMR $(p=0,001)$ sedangkan kelompok kontrol teknik pernafasan $(p=0,047)$. Secara siknifikan tekanan darah pada PMR dan Breathing Control terjadi peneurunan sehingga dapat disimpulkan kedua intervensi ini efektif dalam menurunkan tekanan darah.

Penelitian lain dilakukan (Khatri, Rm, \& Romi, 2012), bertujuan untuk melihat efek secara acak diobati dengan obat dan Progressive Muscle Relaxation Jacobson disertai dengan pemberian obat pada hipertensi di Rumah Sakit Pravara Rural, Loni, Maharashtra negara bagian India. Jumlah sampel yang digunakan sebnyak 59 orang dengan usia 40 sampai 60 tahun. Pada hasil penelitian menunjukan pada kontrol hanya obat 152/90,56 mmHg dan setelah 3 minggu menjadi 150.04/89,6 $\mathrm{mmHg}$, disamping itu hasil tekann darah pada intervensi PMR disertai obat adalah 151,17/92,03 mmhg dan setelah 3 minggu menjadi 142,79/86,56 mmHg dengan hasil akhir yang didaptkan yaitu ( $p$ $<0.0001$ ). Dapat disimpulkan bahwa penurunan tekanan darah secara siknifikan lebih besar pada intervensi PMR Jacobson disertai obat dibandingkan dengan yang hanya obat sehingga latihan PMR Jacobson bisa digunakan sebagai pelengkap atau tambahan intervensi dalam penanganan hipertensi.

Penelitian lain dilakukan oleh (Hahn, Ro, \& Song, 1993), dengan tujuan melihat efek dari pelatihan Biofeedback Thermal yang dikombinasikan Progressive Muscle Relaxation (PMR) dengan pasien hipertensi esensial dalam menurunkan tekanan darah. Jumlah sampel yang di gunakan sebanyak 19 orang perempuan yang didiagnosa hipertensi esensial yang berusia antara 30 dan 59 tahun. Pada hasil penelitian menunjukan tekanan darah sitolik $20,6 \mathrm{mmHg}$ dan tekanan darah diastolic $14,4 \mathrm{mmHg}$ yang dilaukan selama 4 minggu dan didaptkan hasil akhir yaitu $(p<0.002)$. Sehingga dapat disimpulkan Biofeedback Thermal yang dikombinasikan dengan Progressive Muscle Relaxation (PMR) efektif dalam menurunkan tekanan darah.

Penelitian lain yang dilakukan oleh (Cottier, Shapiro, \& Julius, 2015), dengan tujuan melihat efek dari pelatihan Progressive Muscle Relaxation (PMR) dan kelompok kontrol yang diselidiki dalam prespektif randomiced pada percobaan pasien Hipertensi di Rumah Sakit Universitas, Sekolah Kedoktera, Rumah Sakit Kanton, Basel, Swiss. Jumlah sampel yang digunakan sebanyak 50 orang dengan diagnosa hipertensi ringan yang berusia 18-50 tahun. Pada hasil penelitian ini menujukan setelah 22 minggu terjadi penurunan tekanan darah pada pelatihan PMR sebanyak $3 \mathrm{mmHg}$ sedangkan pada kelompok kontrol terjadi penurunan $2 \mathrm{mmHg}$ dan didapatkan hasil akhir yaitu $(p<$ 0,001 ). Dapat disimpulkan terjadi penurunan yang tidak signifikan pada kedua kelompok tersebut sehingga pelatihan yang diberikan dapat digunakan sebagai intervensi dalam menangani penyakit Hipertensi.

\section{KESIMPULAN DAN SARAN}

Setelah pemberian intervensi latihan progressive muscle relaxation, terjadi penurunan tekanan darah pada pasien yang mengalami hipertensi. Hal ini dapat dilihat dari perubahan tekanan darah sebelum dan sesudah pemberian latihan progressive muscle relaxation.

Diharapkan kepada institusi pendidikan di Indonesia menjadikan PMR sebagai bahan pembelajaran terapi non-farmakologi dalam menurunkan tekanan darah. Selain itu diharapkan kepada rumah sakit dan puskesmas agar dapat memberi dan mefasilitasi PMR pada perawat untuk meningkatkan derajat kesehatan yang lebih baik pada pasien hipertensi di rumah sakit maupun di puskesmas. Literature review ini memerlukan intervensi yang lebih lanjut serta intervensi yang lebih lama dan jumlah sampel yang lebih banyak untuk mendapatkan hasil yang maksimal. 


\section{DAFTAR PUSTAKA}

Aalami, M., Jafarnejad, F., \& Modarresgharavi, M. (2016). The effects of progressive muscular relaxation and breathing control technique on blood pressure during pregnancy. https://doi.org/10.4103/1735-9066.180382.

Akmeşe, Z. B., \& Oran, N. T. (2014). Effects of Progressive Muscle Relaxation Exercises Accompanied by Music on Low Back Pain and Quality of Life During Pregnancy. Journal of Midwifery and Women's Health, 59(5), 503-509. https://doi.org/10.1111/jmwh.12176.

Cottier, C., Shapiro, K., \& Julius, S. (2015). Treatment of Mild Hypertension Predictive Value of Indexes of Sympathetic Tone.

Hahn, Y. B., Ro, Y. J., \& Song, H. H. (1993). The Effect of Thermal Biofeedback and Progressive Muscle Relaxation Training in Reducing Blood Pressure of Patients with Essential Hypertension.

Khatri, S. M., Rm, R. M. S., \& Romi, H. N. (2012). Effectiveness of Jacobson' s Relaxation Technique in Hypertension, 1, 16-21.

Kwekkeboom, K. L., Hau, H., Wanta, B., \& Bumpus, M. (2008). Patients' perceptions of the effectiveness of guided imagery and progressive muscle relaxation interventions used for cancer pain. Complementary Therapies in Clinical Practice, 14(3), 185-194. https://doi.org/10.1016/j.ctcp.2008.04.002.

Makassar, dinas kesehatan kota. (2017). profil kesehatan kota makassar tahun 2016.

Muliyati, H., Syam, A., \& Sirajuddin, S. (2010). hubungan pola konsumsi natriun dan kalium serta aktifitas fisik dengan kjadian hipertensi pada pasien rawat jalan di RSUP Wahidin Sudirohusodo Dr Wahidin Sudirohusodo Makassar the correlation of dietary pattern of sodium, potassium, and phisical activity .

Pudiastuti., \& Dewi, R. (2013). penyakit penyakit mematikan. yogyakarta: nuha medika.

Purwanto, S. (2006). Relaksasi dzikir. Suhuf, XVIII (1), 39-48.

Resti, I. B. (2014). teknik relaksasi otot untuk mengurangi stres pada penderita asma, 2(1), 1-20. https://doi.org/10.22219/jipt.v2i1.1766.

Sheu, S., Irvin, I. B. L., Mar, I. H. L. I. C., Lin, H., \& Mar, C. (2003). Effects of Progressive Muscle Relaxation on Blood Pressure and Psychosocial Status for Clients with Essential Hypertension in Taiwan, 14-19.

Sinubu, Risky Brian dan Rondonuwu, R. (2015). hubungan beban kerja dengan keadian hipertensi pada tenaga pengajar di SMA N 1 Amurang kabupaten minahasa selatan, 3, 1-8.

Trisnowiyanto, B. (2015). pengaruh immediet instrumen music hearing therapy dengan progressive muscle relaxation exercise terhadap rest heart reat, 11(2), 71-78.

Triyanto, E. (Ed.). (2014). pelayanan keperawatan bagi penderita hipertensi secara terpadu. yogyakarta: graha ilmu.

wijaya, andra saferi dan putri yessiemariza. (2013). KMB keperawatan medikal bedah ( keperawatan dewasa) (1st ed.). yogyakarta: nuha medika.

Zaenurrohmah, D. H. R. D. \& R. (2017). Hubungan pengetahuan dan riwayat hipertensi dengan tindakan pengendalian tekanan darah pada lansia, (June 2017), 174-184. https://doi.org/10.20473/jbe.v5i2.2017.174-184. 